\title{
Balance Assessment in Subacute Stroke Patients Using the Balance Control Trainer (BalPro)
}

\author{
Jin Won Song, $\mathrm{MD}^{1}$, Jong Min Kim, $\mathrm{MD}^{1}$, Youn Soo Cheong, $\mathrm{MD}^{2}$, \\ Yang-Soo Lee, $\mathrm{MD}^{2}$, Seong Min Chun, $\mathrm{MD}^{3}$, Yu-Sun Min, $\mathrm{MD}^{2,3}$, Tae-Du Jung, $\mathrm{MD}^{2,3}$ \\ ${ }^{1}$ Department of Rehabilitation Medicine, Daegu Fatima Hospital, Daegu; \\ ${ }^{2}$ Department of Rehabilitation Medicine, Kyungpook National University College of Medicine, Daegu; \\ ${ }^{3}$ Department of Rehabilitation Medicine, Kyungpook National University Medical Center, Daegu, Korea
}

Objective To demonstrate the efficacy of the balance control trainer (BCT), developed for training patients with balance problems, as a balance assessment tool in subacute stroke patients.

Methods A prospective cross-sectional study was carried out on 38 subacute stroke patients in their first episode of a stroke, and having the ability to maintain a standing position without aid for at least 5 minutes. Patients were assessed using the BCT (BalPro) $43.7 \pm 35.7$ days after stroke. The balance was assessed using the Berg Balance Scale (BBS), the Timed Up and Go Test (TUG), a 10-meter walking test (10mWT), a 6-minute walking test (6MWT), and the Korean version of the Modified Barthel Index. The correlation and validity between the BCT and various balance assessments were analyzed.

Results Statistically significant linear correlations were observed between the BCT score and the BBS ( $r=0.698$, $\mathrm{p}<0.001)$. A moderate to excellent correlation was seen between the BCT score and 11 of the 14 BBS items. The BCT scores and other secondary outcome parameters (6MWT $r=0.392, p=0.048$; TUG $r=-0.471, p=0.006$; 10mWT $\mathrm{r}=-0.437, \mathrm{p}=0.012$ ) had a moderate correlation.

Conclusion Balance control training using the BCT (BalPro) showed significant statistical correlation with the BBS, and could therefore be a useful additional balance assessment tool in subacute stroke patients.

Keywords Postural balance, Stroke, Posturography, Berg Balance Scale

\section{INTRODUCTION}

Hemiparesis is the most common neurological deficit in patients with a stroke [1]. Stroke patients with hemipa- resis have balance impairments [2], which are implicated in a risk of falling, mortality, and high socio-economic costs [3-6]. Various underlying complications give rise to balance impairment, such as joint motion limitation,

Received May 3, 2016; Accepted August 24, 2016

Corresponding author: Tae-Du Jung

Department of Rehabilitation Medicine, Kyungpook National University College of Medicine, 130 Dongdeok-ro, Jung-gu, Daegu 41944, Korea. Tel: +8253-420-5311, Fax: +82-53-423-0389, E-mail: teeed0522@hanmail.net

ORCID: Jin Won Song (http://orcid.org/0000-0001-7300-3462); Jong Min Kim (http://orcid.org/0000-0002-4748-2030); Youn Soo Cheong (http://orcid. org/0000-0001-7105-4776); Yang-Soo Lee (http://orcid.org/0000-0002-8855-1231); Seong Min Chun (http://orcid.org/0000-0002-2174-8742); Yu-Sun Min (http://orcid.org/0000-0003-0373-0538); Tae-Du Jung (http://orcid.org/0000-0002-1636-8665).

@ This is an open-access article distributed under the terms of the Creative Commons Attribution Non-Commercial License (http://creativecommons.org/ licenses/by-nc/4.0) which permits unrestricted noncommercial use, distribution, and reproduction in any medium, provided the original work is properly cited. Copyright $\odot 2017$ by Korean Academy of Rehabilitation Medicine 
muscle weakness, altered muscular tone, sensory deficits, abnormal postural reactions, and cognitive impairments [7].

Efficient therapeutic approaches based on the appropriate assessment of balance are required; however, the best tools for balance evaluation in stroke patients are still under debate $[8,9]$. Balance can be assessed by simple questionnaires or instrumented posturography. Simple questionnaires includes the Berg Balance Scale (BBS) [10], the Time Up and Go test (TUG) [11], the Brunel Balance Assessment [12], the Community Balance and Mobility Scale [13], the Postural Assessment Scale for Stroke patients [14], the 10-meter walking test (10mWT) [15], and the 6-minute walking test (6MWT) [16]. Instrumented posturography is a computerized technique which quantifies either the static or dynamic conditions [17]. In 1986, the first commercially available testing system was the EquiTest system of NeuroCom International Inc. [18]. Subsequently, many posturographies have been developed-the Synapsys Posturography System (Synapsys, Marseille, France), the SMART Balance Master (Natus Medical Inc., Pleasanton, CA, USA), and the Tetrax Interactive Static Posturography System (Sunlight Medical Ltd., Ramat Gan, Israel). These systems assess the postural stability by measuring the fluctuation of body weight distribution on foot plates [19]. The quantitative measuring of the center of mass (COM) by utilizing force plates indicates postural sway and weight distributions. Postural reactions are quantified while keeping the feet together and standing on one leg. Sawacha et al. [20] showed that post-stroke patients could take advantage of the quantitative posturography in balance assessment.

However, these instruments measure only the horizontal plane movement (such as postural sway, weight distribution, or related measures) rather than vertical movement (an up-and-down movement of the COM).

A previous study on balance control training using the balance control trainer (BCT) shows a remarkable training effect on improving balance disability [21]. Furthermore, the training effect was measured using several outcome measurements. The BCT was developed to allow training not only in the horizontal plane but also in the vertical plane, and can measure both a balance abnormality and disability (such as a static or dynamic balance).

In the present study, our research team attempted to confirm the correlation between the BCT score and other balance assessment tools, and verify whether the BCT score could be used as a balance assessment in subacute stroke patients.

\section{MATERIALS AND METHODS}

\section{Participants}

Between October 2014 and April 2016, a total of 49 subacute stroke patients were recruited from Kyungpook National University College of Medicine and Daegu Fatima Hospital, Daegu, Korea.

The inclusion criteria were as follows: the first episode of a stroke (an infarction or a hemorrhage), the ability to maintain a standing position without aid for at least 5 minutes, and the Mini-Mental State Examination $\geq 24$. The exclusion criteria were as follows: cognitive impairment (Mini-Mental State Examination $<23$ ), a severe balance dysfunction (BBS $<1$ ), vestibular disorders, paroxysmal vertigo, visuospatial neglect syndrome, a visual disturbance, presence of other neurological conditions, any orthopedic disease involving the lower limbs, and a high risk of cardiac or other medical problems.

A total of 38 patients were included in this study (Fig. 1). The general characteristics are shown in Table 1. This study was conducted by Kyungpook National University, and approved by the Institutional Review Board of Kyungpook National University (IRB No. 2014-01-019001). A written informed consent was obtained from all participants in the study.

\section{The balance control trainer}

BalPro (Man\&Tel, Gumi, Korea), a lower limb rehabilitation machine, was used for the initial balance assessment. The BCT consists of a balance board, two foot



Fig. 1. A flowchart of this study. 
Table 1. Demographic factors of the patients enrolled in this study ( $\mathrm{n}=38)$

\begin{tabular}{|cc}
\hline \multicolumn{1}{c}{ Characteristic } & Value (\%) \\
\hline Sex & \\
\hline Male & $23(61)$ \\
\hline Female & $15(39)$ \\
\hline Age (yr) & $55.32 \pm 13.86$ \\
\hline Etiology of stroke & \\
\hline Ischemic & $25(66)$ \\
\hline Hemorrhagic & $13(34)$ \\
\hline Lesion location & \\
\hline Supra-tentorial & $32(84)$ \\
\hline Infra-tentorial & $6(16)$ \\
\hline Mean days from onset & $43.7 \pm 35.7$ \\
\hline Affected side & \\
\hline Right & $22(58)$ \\
\hline Left & $15(39)$ \\
\hline Both & $1(3)$ \\
\hline
\end{tabular}

Values are presented as number (\%) or mean \pm standard deviation. plates (measures the weight distribution and expresses it in the form of a percentage), a tilting sensor (measures the thigh inclination during knee flexion and extension movement, and identifies the subject's vertical movement, i.e., up-and down movement of COM, by the degree of inclination of the thigh), a computer system (includes the software required to process all the movement data), a display screen (visualizes the input data), and safety bars with a harness (to prevent patients from falling) (Fig. $2 \mathrm{~A})$. The height of the display screen is adjusted at the patient's eye level, and a harness applied to prevent falling. The software translates the pressure on the balance board into a horizontal cursor movement, and the tilting movement on the lateral side of the thigh into a vertical cursor movement on the screen. The cursor moves horizontally and vertically; it then combines both the directional movements, which makes the cursor move diagonally. By moving a hand-shaped cursor on the screen, the patients can pick fruit in a fruit-harvesting electronic game (Fig. 2B). The difficulty of the game can be adjusted by varying the limitation times and the number of fruits. In our study, the game consisted of 10 repetitive stages,


Fig. 2. The balance control trainer (BalPro). (A) The balance control trainer consists of a balance board, a tilting sensor, a computer system, a display screen, and safety bars with a harness. (B) The fruit-harvesting electronic game. The top figure means the easiest level with only one target (fruit) and a large-sized indicator (hand), the middle figure stands for moderate difficulty with several targets ( 5 fruits) and a middlesized indicator, and the bottom figure shows the highest level of difficulty with many targets (20 fruits) and a small-sized indicator. 
and 5 fruits randomly appeared on the screen; this is the fifth mode of difficulty among the 7 available modes of difficulty.

The difficulty level of the BCT differs from ' 1 ' being the simplest mode with one fruit, to ' 7 ' being the highest difficulty mode with 7 fruits. The limitation time of each stage was set to 2 minutes. The game was performed under the supervision of a rehabilitation medicine physician. After conclusion of the game, the score was automatically calculated by the computer, as the total sum of fruits picked. The score indirectly indicates a side to side center of mass shifting ability and vertical movements. In order for the patients to become familiar with the BCT environment, three rounds of the game were played, and the best outcome was selected as the result.

\section{The balance assessment}

BBS was used as the primary balance outcome measure for analysis. The TUG, 10mWT, 6MWT, and the Korean version of the Modified Barthel Index (K-MBI) were used as the clinical outcome measurements to evaluate the functional ability of patients.

A total of 14 items that require the subjects to maintain positions or complete movement tasks of varying difficulty are easily assessable by BBM. These include: sitting unsupported, sit-to-stand, stand-to-sit, transferring, standing unsupported, standing with the eyes closed, standing with the feet together, reaching forward with an outstretched arm, turning to look behind, picking up an object from the floor, turning around, placing alternate feet on a stool, one foot forward, and a single-limb stance. The degree of success in achieving each task is scored from 0 (unable) to 4 (independent), and the final measure is the sum of all the scores. More than 40 points indicate that the subject is independent and has a lesser risk of falling [22]. Used frequently in a clinical setting, BBS has shown excellent reliability in patients with acute stroke [11], and also showed a moderate to large responsiveness at detecting changes within 2-12 weeks [23].

TUG is a single-item test that requires the subject to stand up, walk 3 meters, turn back, and sit down again. The total time during the sequential movements is recorded. A time of $<10$ seconds indicates normal mobility, 11-20 seconds is the normal limit for disabled patients, and $>20$ seconds is considered to be abnormal. Since it uses agreement in a stop-watch duration rather than rat- ing scales, it is probably the most reliable functional balance test [24].

An assessment tool of functional mobility measuring the time taken to walk a 10-meter distance without assistance, is the $10 \mathrm{mWT}$ [25]. It records the time a patient takes to walk 10 meters at a normal, comfortable speed.

The 6MWT is a one-time measure of the functional status of patients [26]. The patients walk along a 30-meter hallway for 6 minutes, and the total distance covered is recorded.

The K-MBI scale measures the performance of daily living activities. Although the scale is regarded as being reliable, its use in stroke medicine clinical trials is variable [27]. The scale has demonstrated high inter-rater reliability and test-retest reliability. Ten variables are used, including bowel, urinary, grooming, toilet use, feeding, transfer, walking, dressing, climbing stairs, and bathing.

\section{The validity and reliability assessment of the BCT (BalPro)}

The validity of the BCT was processed by comparing it with the BBS. A total of 38 patients participated in this study, and performed the BCT and BBS tests.

To evaluate the test-retest reliability, a preliminary study of 3 normal participants was conducted. These subjects were measured by BCT, which was repeated the following day.

The inter-rater reliability and intra-rater reliability was not assessed as the BCT score was automatically calculated by the computer.

\section{Statistical analysis}

For the statistical analysis, we used the SPSS ver. 20.0 (IBM SPSS, Armonk, NY, USA) for Windows. The normal distribution of the variables was confirmed by Kolmogorov-Smirnov tests. The chi-square test was applied for the nonparametric variables. A paired-sampled t-test was computed, and the correlation between both the BCT and the BBS was examined using Bland-Altman plots. The Pearson correlation coefficient test was applied to assess the association between the BCT score, BBS, TUG, 10mWT, 6MWT, and K-MBI. A p-value of $\leq 0.05$ was considered to be statistically significant. 


\section{RESULTS}

A total of 38 patients (23 males and 15 females) with a mean age of $55.32 \pm 13.86$ years were enrolled in the study. The mean time from onset of their stroke was $43.7 \pm 35.7$ days. Of these, 25 patients suffered from an ischemic infarction, and 13 patients suffered from a hemorrhagic stroke. The side affected by stroke was the right one in 22 patients, the left one in 15 patients, and both sides in 1 patient (Table 1 ). The group of patients with a supratentorial lesion consisted of the following: 17 middle cerebral artery (MCA) territory infarction (45\%), 2 anterior cerebral artery (ACA) territory infarction (5\%), 1 MCA and ACA watershed infarction (3\%), 8 intra-cerebral hemorrhage $(\mathrm{ICH})$ on the basal ganglia $(21 \%), 3 \mathrm{ICH}$ on the frontal lobe (8\%), and $1 \mathrm{ICH}$ on the temporal lobe (3\%). The group of patients with an infra-tentorial lesion consisted of 6 with brain stem infarction (16\%).

The validity of the BCT and the BBS was confirmed by the paired-samples t-test and the Bland and Altman plots (Fig. 3). These high correlations acknowledge the results of BCT to be similar as those obtained with the BBS.

As a result of the test-retest reliability, the BCT score of 3 participants was the same in both the initial and the one-day delay interval test (Cohen's kappa value=1).

The mean and standard deviations values for the balance assessment parameters were as follows: BCT score

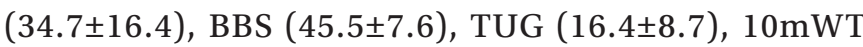
$(17.0 \pm 10.3)$; $6 \mathrm{MWT}(327.2 \pm 137.2)$, and K-MBI $(70.3 \pm 17.3)$



Fig. 3. The Bland and Altman plot for the Berg Balance Scale (BBS) and the BalPro score. The dotted line (the middle one) represents the mean difference of the BBS and the BalPro score. Both extremity lines indicate upper and lower correlations (SD 1.96).
(Table 2).

A positive correlation was observed between the BCT score and the BBS, which was statistically significant $(\mathrm{r}=0.698, \mathrm{p}<0.001)$ (Table 3$)$. The correlation between the BCT score and each item of the BBS was evaluated. A moderate to excellent correlation with statistical significance was seen between the BCT score and each of the 11 out of 14 BBS parameters: sit-to-stand ( $r=0.494, p=0.005)$, standing unsupported $(\mathrm{r}=0.432, \mathrm{p}=0.015)$, transferring $(\mathrm{r}=0.557, \mathrm{p}=0.001)$, standing with the eyes closed $(\mathrm{r}=0.478$, $\mathrm{p}=0.007)$, standing with the feet together $(\mathrm{r}=0.738, \mathrm{p}<$ $0.001)$, reaching forward with an outstretched arm ( $r=$ $0.565, \mathrm{p}=0.001)$, picking up an object from the floor $(\mathrm{r}=$ $0.561, \mathrm{p}=0.001)$, turning around $(\mathrm{r}=0.614, \mathrm{p}<0.001)$, placing alternate feet on a stool $(r=0.546, p=0.001)$, one foot forward $(r=0.695, p<0.001)$, and a single-limb stance $(\mathrm{r}=0.590, \mathrm{p}<0.001)$. There was no statistical correlation between the BCT score and the following 3 parameters of

Table 2. A summary of the six balance assessment tests

\begin{tabular}{lcc}
\hline \multicolumn{1}{c}{ Test } & Mean \pm SD & $\mathbf{9 5 \% ~ C I ~}$ \\
\hline BCT score & $34.7 \pm 16.4$ & $29.5-39.9$ \\
BBS & $45.5 \pm 7.6$ & $43.1-47.9$ \\
TUG $(\mathrm{s})$ & $16.4 \pm 8.7$ & $13.5-19.4$ \\
10mWT $(\mathrm{s})$ & $17.0 \pm 10.3$ & $13.4-20.6$ \\
6MWT $(\mathrm{m})$ & $327.2 \pm 137.2$ & $274.4-379.9$ \\
K-MBI & $70.3 \pm 17.3$ & $64.8-75.8$ \\
\hline
\end{tabular}

SD, standard deviation; CI, confidence interval; BCT, balance control trainer; BBS, Berg Balance Scale; TUG, Timed Up and Go test; 10mWT, 10-meter walking test; 6MWT, 6-minute walking test; K-MBI, Korean version of Modified Barthel Index.

Table 3. The correlation between BCT score and other balance assessment tools

\begin{tabular}{lccc}
\hline & $\begin{array}{c}\text { Pearson correlation } \\
\text { coefficient }\end{array}$ & $\mathbf{R}^{2}$ & p-value \\
\hline BBS & 0.698 & 0.487 & $<0.001$ \\
TUG & -0.471 & 0.222 & 0.006 \\
10mWT & -0.437 & 0.191 & 0.012 \\
6MWT & 0.392 & 0.154 & 0.048 \\
K-MBI & 0.281 & 0.079 & 0.087 \\
\hline
\end{tabular}

BCT, balance control trainer; BBS, Berg Balance Scale; TUG, Timed Up and Go test; 10mWT, 10-meter walking test; 6MWT, 6-minute walking test; K-MBI, Korean version of Modified Barthel Index. 
Table 4. The relationship between the BCT score and 14 BBS items

\begin{tabular}{|c|c|c|}
\hline & $\begin{array}{l}\text { Pearson correlation } \\
\text { coefficient with } \\
\text { BCT score }\end{array}$ & p-value \\
\hline Sitting to standing & 0.518 & 0.001 \\
\hline Standing unsupported & 0.472 & 0.003 \\
\hline Sitting unsupported & $-{ }^{\text {a) }}$ & $-^{\text {a) }}$ \\
\hline Standing to sitting & 0.244 & 0.140 \\
\hline Transfers & 0.488 & 0.002 \\
\hline Standing with eyes closed & 0.373 & 0.021 \\
\hline Standing with feet together & 0.612 & $<0.001$ \\
\hline $\begin{array}{l}\text { Reaching forward } \\
\text { with outstretched arm }\end{array}$ & 0.476 & 0.003 \\
\hline $\begin{array}{l}\text { Retrieving object } \\
\text { from floor }\end{array}$ & 0.568 & $<0.001$ \\
\hline Turning to look behind & 0.258 & 0.118 \\
\hline Turning $360^{\circ}$ & 0.577 & $<0.001$ \\
\hline $\begin{array}{l}\text { Placing alternate foot } \\
\text { on stool }\end{array}$ & 0.537 & 0.001 \\
\hline $\begin{array}{l}\text { Standing with one foot } \\
\text { in front }\end{array}$ & 0.622 & $<0.001$ \\
\hline Standing on one foot & 0.501 & 0.001 \\
\hline
\end{tabular}

BCT, balance control trainer; BBS, Berg Balance Scale.

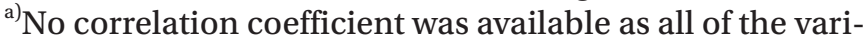
ables of the BBS were the same value.

the BBS: sitting unsupported ( $\mathrm{r}=$ none, $\mathrm{p}=$ none), standto-sit $(\mathrm{r}=0.263, \mathrm{p}=0.153)$, and turning to look behind $(\mathrm{r}=$ $0.221, \mathrm{p}=0.232$ ) (Table 4).

An adequate positive correlation was also observed between the BCT score and the BBS in patients with a high BBS (BBS $>40)$, which showed statistical significance $(\mathrm{r}=0.543, \mathrm{p}=0.005)$. However, there was a poor correlation between the BCT score and the BBS in patients with a low BBS (BBS $\leq 40)(\mathrm{r}=0.158, \mathrm{p}=0.607)$.

There were positive and moderate correlation between the BCT score and the 6MWT ( $r=0.392)$, and negative and moderate correlations between the BCT score and the TUG $(\mathrm{r}=-0.471)$, the 10mWT $(\mathrm{r}=-0.437)$. All the observed correlations were statistically significant $(\mathrm{p}=0.048$, $\mathrm{p}=0.012$, and $\mathrm{p}=0.087$ ).

However, no statistical correlation was seen between the BCT score and the K-MBI $(\mathrm{r}=0.281, \mathrm{p}=0.087)$ (Table 3, Fig. 4).

\section{DISCUSSION}

This is the first study confirming the relationship between the BCT score and other balance control parameters in subacute stroke patients. Statistically significant associations between the BCT score and other balance control parameters were obtained in this study.

The BBS is a functional balance assessment tool with excellent inter-rater reliability; however, the sensitivity is poor in moderate balance impairment [10]. The total sum of each variable indicates the functional balance of the patient: more than 40 points (subject is independent), 21-40 points (subject can walk with assistance), and less than 21 points (subject needs a wheelchair to ambulate).

Correlations between the BCT score and each of the 14 items of the BBS were analyzed. Although there were significant statistical correlations between the BCT score and the BBS in 11 items, 3 factors showed poor correlations: sitting unsupported, stand-to-sit, and turning to look behind. These items are relatively easy to perform as compared to the other items. Because our study included patients who are able maintain a standing position for 5 minutes, almost every patient achieved 4 points in sitting unsupported, stand-to-sit, and turning to look behind. Since the BCT assessed balance with its two foot plate and knee joint sensor, the BCT could not directly assess sitting unsupported, standing with the feet together, placing alternate feet on a stool, one foot forward and single-limb stance. Hence, BCT was unable to assess the dynamic balance with complex movements, including transferring, standing with the eyes closed, reaching forward with an outstretched arm, turning to look behind, and turning around.

The BCT showed a statistically significant moderate positive correlation with the BBS; in the high BBS (BBS $>40$ ) group, BCT could be a more effective balance assessment tool in patients with moderate to good balance control. However, a poor correlation was seen between the BCT and a low BBS (BBS $\leq 40)$ group, which could be due to a number of reasons. First, the BBS evaluates the multidimensional balance including up-and-down, sideto-side and backward-and-forward, which is assessed by transferring, one foot forward, reaching forward with an outstretched arm, turning to look behind, and turning around. However, the BCT can only assess the twodimensional balance, including up-and-down and side- 
(A)

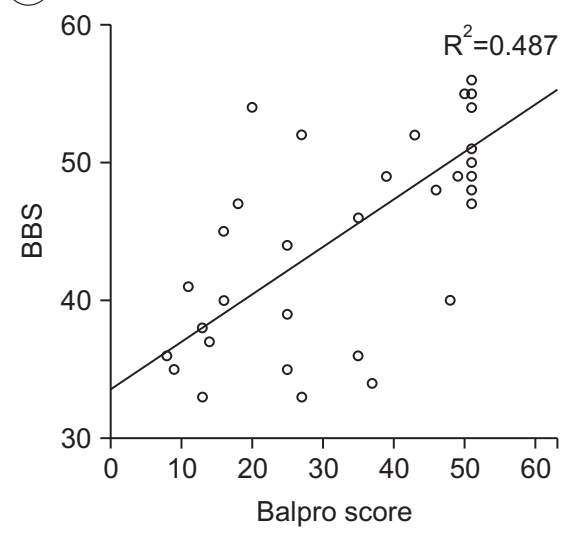

(B)



(C)



(D)

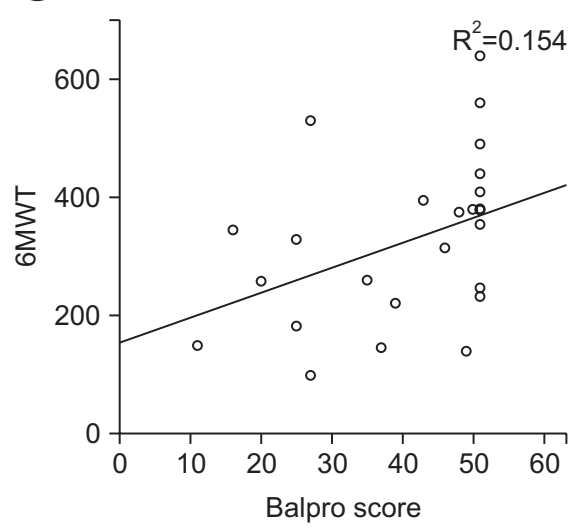

(E)

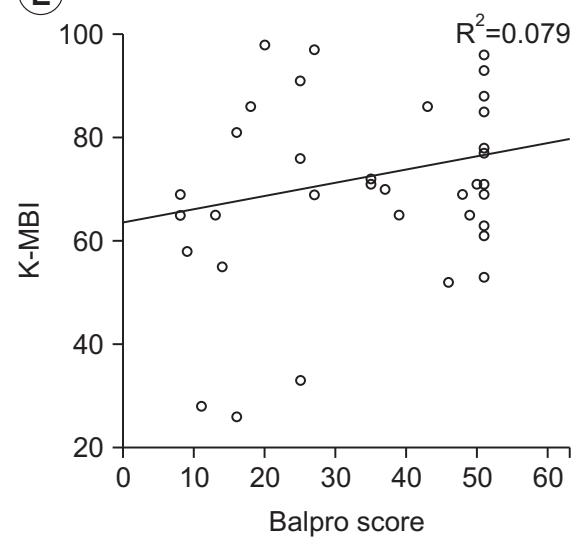

Fig. 4. A scatter plot between the BalPro score and other balance parameters. (A) Berg Balance Scale (BBS), (B) Timed Up and Go (TUG), (C) 10-meter walking test (10mWT), (D) 6-minute walking test (6MWT), and (E) Korean version of the Modified Barthel Index (K-MBI).

to-side, with its two foot plate and knee joint sensor. Hence, due to these mechanical causes, results would differ between the BCT and the BBS. Second, as mentioned in Material and Methods section, our BCT protocol consisted of ten repetitive stages of the fifth difficulty mode from among seven difficulty modes. The repetitive test with the same level of difficulty causes easy distraction for the patients, resulting in negative effects on the BCT score. To avoid these issues, changing difficulty level of the BCT could resolve the issues, by distinguishing between patients with balance problem and distracted patients. For instance, BCT should begin with easy level, gradually raising the difficulty level, such that the patient undergoes several levels from moderate to easy to difficult. Afterward patients will undergo several steps of easy difficulty level among moderate to high difficulty mode.
If a patient has trouble passing the easy steps previously cleared easily, the test procedure should be stopped, as this could indicate distraction. In this ways, assessment methods could be improved by modifying the protocol. Third, the narrow range of BBS values (33-40) could result in the poor correlation in low BBS group. Since inclusion criteria of this study required patients with sufficient endurance and strength to follow the BCT training, all BBS points of the patient were 33 and above. In addition, age could be another reason for poor correlation between the BCT and the low BBS. The age of $10(77 \%)$ of the patients was $>65$ among the low BBS group. However, the age of $3(12 \%)$ patients was $>65$ in the high BBS group (BBS $>40$ ). The mean age of the patients with a low BBS score was $65.0 \pm 10.5$, which is higher than $50.3 \pm 12.8$ of the high BBS score group. Also, the mean test time from the di- 
agnosis was shorter in the low BBS group. The mean test time from the diagnosis was $33.15 \pm 19.62$ days in the low BBS group, which is a shorter duration than $49.20 \pm 41.04$ days in the high BBS group.

With its unique movement training system, the BCT achieves greater improvements in balance and mobility in stroke patients [21]. Although other computerized dynamic posturography measures only the horizontal body weight distribution, the BalPro training system includes not only horizontal movement, but also vertical movement. By training vertical movement of the center of gravity, patients learn to control adequate vertical movements, which is highly important in a gait cycle. Therefore, an improvement of their balance and gait could be achieved. Moreover, the BCT score can be easily obtained while patients undergo balance training without the assistance of another person. The balance evaluation with simple questionnaires requires additional time and personnel from the training session to assess balance control. The balance evaluation with an instrument (computerized posturography) also requires a person who instructs the patient to get into a specific posture. Tetrax requires a person who can instruct eight standard positions for checking balance. However, the BCT score can be viewed immediately after the training session and therefore, it could represent a time-cost effective method for evaluating balance control.

In addition, the level of difficulty of the BCT game can be adjusted. While other instrumented posturographies only evaluate the weight distribution of the patient, the BCT also evaluates the functional ability of patients with its real-time gaming. The physician can apply an easy mode of difficulty for patients with poor balance control, and a higher level for patients with good balance control. By using an appropriate mode of difficulty, patients can be assessed effectively, regardless of their balance control level.

Other posturographies measure the pressure values of backward-and-forward and side-to-side movements while subjects are performing specific tasks (eye closing, surface swaying, etc.). By measuring these four-way horizontal movements, other posturographies represent the current balance control status. However, the BCT does not measure backward-and-forward movements as do other posturographies. The BCT measures vertical up-and-down movements with its unique thigh-tilting sensor, which may result in different conclusions. By applying another sensor to measure backward-and-forward movements, the BCT could be a more effective tool as a three-dimensional balance assessment.

There are some limitations when using the BCT as a balance assessment tool. First, the patients should have adequate muscle power and cognition to follow detailed instructions. Second, the number of patients in our study was relatively small compared to other studies. Third, our study did not include patients with poor balance control. Fourth, an attached harness of the BCT could have some influence in assessing the balance of individuals. Patients with poor trunk control could have a chance to receive a higher score by the aid of an attached harness. A further study should include patients with a severe to mild degree of balance problem, in order to evaluate the usefulness of the BCT as a balance assessment tool.

In conclusion, a balance assessment using the BCT could represent a useful tool for evaluating functional balance control achievement in subacute stroke patients due to the significant statistical correlation observed between the BCT and the BBS.

\section{CONFLICT OF INTEREST}

No potential conflict of interest relevant to this article was reported.

\section{REFERENCES}

1. Gresham GE, Duncan PW, Stason WB, Adams HP, Adelman AM, Alexander DM, et al. Post-stroke rehabilitation. Rockville: US Department of Health and Human Services, Public Health Service, Agency for Health Care Policy and Research; 1995.

2. Tyson SF, Hanley M, Chillala J, Selley A, Tallis RC. Balance disability after stroke. Phys Ther 2006;86:30-8.

3. Lamb SE, Ferrucci L, Volapto S, Fried LP, Guralnik JM. Risk factors for falling in home-dwelling older women with stroke: the Women's Health and Aging Study. Stroke 2003;34:494-501.

4. Harris JE, Eng JJ, Marigold DS, Tokuno CD, Louis CL. Relationship of balance and mobility to fall incidence in people with chronic stroke. Phys Ther 2005;85:1508.

5. Belgen B, Beninato M, Sullivan PE, Narielwalla K. 
The association of balance capacity and falls selfefficacy with history of falling in community-dwelling people with chronic stroke. Arch Phys Med Rehabil 2006;87:554-61.

6. Chen IC, Cheng PT, Hu AL, Liaw MY, Chen LR, Hong $\mathrm{WH}$, et al. Balance evaluation in hemiplegic stroke patients. Chang Gung Med J 2000;23:339-47.

7. Bonan IV, Colle FM, Guichard JP, Vicaut E, Eisenfisz M, Tran Ba Huy P, et al. Reliance on visual information after stroke. Part I: balance on dynamic posturography. Arch Phys Med Rehabil 2004;85:268-73.

8. Foley N, Peireira S, Cotoi A, Serrato J, Dukelow S, Sequeira $\mathrm{K}$, et al. Mobility and the lower extremity [Internet]. London: Evidence-Based Review of Stroke Rehabilitation; 2016 [cited 2017 Mar 1]. Available from: http://www.ebrsr.com/evidence-review/9-mobilityand-lower-extremity.

9. Geurts AC, de Haart M, van Nes IJ, Duysens J. A review of standing balance recovery from stroke. Gait Posture 2005;22:267-81.

10. Berg K, Wood-Dauphinee S, Williams JI. The Balance Scale: reliability assessment with elderly residents and patients with an acute stroke. Scand J Rehabil Med 1995;27:27-36.

11. Flansbjer UB, Holmback AM, Downham D, Patten C, Lexell J. Reliability of gait performance tests in men and women with hemiparesis after stroke. J Rehabil Med 2005;37:75-82.

12. Tyson SF, DeSouza LH. Development of the Brunel Balance Assessment: a new measure of balance disability post stroke. Clin Rehabil 2004;18:801-10.

13. Howe JA, Inness EL, Venturini A, Williams JI, Verrier MC. The Community Balance and Mobility Scale: a balance measure for individuals with traumatic brain injury. Clin Rehabil 2006;20:885-95.

14. Benaim C, Perennou DA, Villy J, Rousseaux M, Pelissier JY. Validation of a standardized assessment of postural control in stroke patients: the Postural Assessment Scale for Stroke Patients (PASS). Stroke 1999;30: 1862-8.

15. Perera S, Mody SH, Woodman RC, Studenski SA.
Meaningful change and responsiveness in common physical performance measures in older adults. J Am Geriatr Soc 2006;54:743-9.

16. Eng JJ, Dawson AS, Chu KS. Submaximal exercise in persons with stroke: test-retest reliability and concurrent validity with maximal oxygen consumption. Arch Phys Med Rehabil 2004;85:113-8.

17. Barozzi S, Socci M, Soi D, Di Berardino F, Fabio G, Forti S, et al. Reliability of postural control measures in children and young adolescents. Eur Arch Otorhinolaryngol 2014;271:2069-77.

18. Furman JM. Posturography: uses and limitations. Baillieres Clin Neurol 1994;3:501-13.

19. Kohen-Raz R. Application of tetra-ataxiametric posturography in clinical and developmental diagnosis. Percept Mot Skills 1991;73:635-56.

20. Sawacha Z, Carraro E, Contessa P, Guiotto A, Masiero $\mathrm{S}$, Cobelli C. Relationship between clinical and instrumental balance assessments in chronic post-stroke hemiparesis subjects. J Neuroeng Rehabil 2013;10:95.

21. Lee SH, Byun SD, Kim CH, Go JY, Nam HU, Huh JS, et al. Feasibility and effects of newly developed balance control trainer for mobility and balance in chronic stroke patients: a randomized controlled trial. Ann Rehabil Med 2012;36:521-9.

22. Shumway-Cook A, Baldwin M, Polissar NL, Gruber W. Predicting the probability for falls in communitydwelling older adults. Phys Ther 1997;77:812-9.

23. Wood-Dauphinee S, Berg K, Bravo G, Williams JI. The Balance Scale: responding clinically meaningful changes. Can J Rehabil 1997;10:35-50.

24. Yelnik A, Bonan I. Clinical tools for assessing balance disorders. Neurophysiol Clin 2008;38:439-45.

25. Wade DT. Measurement in neurological rehabilitation. Oxford: Oxford University Press; 1992.

26. Richards CL, Malouin F, Dean C. Gait in stroke: assessment and rehabilitation. Clin Geriatr Med 1999; 15:833-55.

27. Sulter G, Steen C, De Keyser J. Use of the Barthel index and modified Rankin scale in acute stroke trials. Stroke 1999;30:1538-41. 